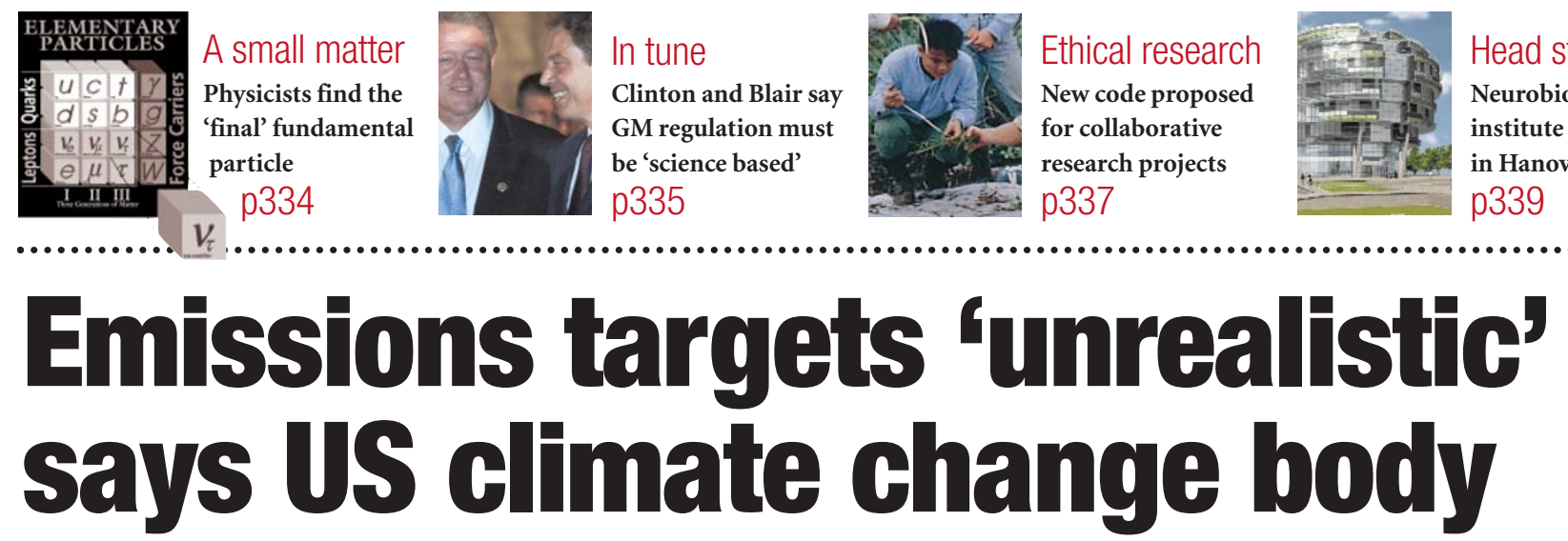

Colin Macilwain, Washington

US climate-change activists are up in arms again. But for once it is not against the fossil-fuel lobby. This time the focus of their ire is one of their strongest supporters the Pew Center on Global Climate Change.

One of the main organizations working for cuts in US greenhouse-gas emissions, the Pew Center has issued a statement saying that the emissions targets set by the 1997 Kyoto Protocol are unrealistic and will eventually have to be renegotiated. Eileen Claussen, the centre's president and former chief negotiator on climate change issues at the US state department, says that "few national governments" will reach their targets for 2008-12.

"There is nothing wrong with ambitious targets, but they have to be grounded in reality," Claussen said in remarks delivered privately in London last month, and repeated publicly in Washington last week at a meeting of scientists and economists who advise the Pew Center.

"The targets in the Kyoto Protocol cannot and will not be met on the established timetable in the United States and elsewhere," said Claussen. "By adhering to unrealistic targets that will be very difficult, if not impossible to meet, we provide the Protocol's opponents with additional ammunition in their efforts to shoot the treaty down."

The Pew Center was established in 1998 by the Pew Charitable Trusts to educate the public on climate-change issues and to encourage reductions in greenhouse-gas emissions. It operates in partnership with a group called the Business Environmental Leadership Council, which includes Boeing and DuPont, but receives no financial support from it.

Claussen still believes that "the good qualities of the Kyoto Protocol vastly outweigh its flaws" and she wants negotiators, who will meet in The Hague this November to finalize the protocol, to implement firm rules on how the treaty will operate before considering revisions to the targets. "If, after ensuring that the framework reflects these priorities, we need to renegotiate the targets or timetables - and I suspect we will — then so be it."

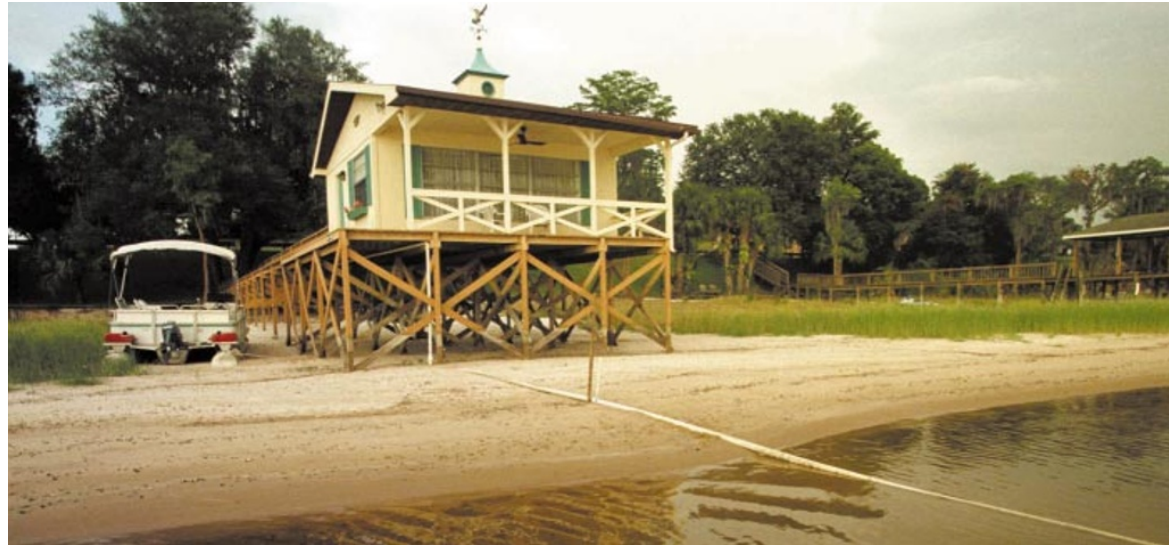

High and dry: avoiding droughts like this one in Florida could require achievable emissions targets.

The remarks were welcomed by some climatologists at the Washington meeting. "I agree with everything she said," says Tom Wigley, senior scientist at the National Center for Atmospheric Research at Boulder, Colorado. "The targets are too much, too soon. She is echoing what many economists believe, that a more moderate approach is going to be a much better approach."

But Claussen's blunt characterization of the targets has alarmed environmental groups, who believe that the Kyoto Protocol is the main driving force for global action by governments and industry to cut emissions.

Claussen's pessimism is not shared, at least in public, by other groups who support action

\title{
Ensembl gets a Wellcome boost
}

\section{Declan Butler}

Britain's Wellcome Trust announced last week that it is contributing $\mathfrak{E 8 . 8}$ million (\$13.4 million) to Ensembl, the decentralized annotation project for the human genome.

The funding, over five years, is a vote of confidence for Ensembl's vision of sequence annotation being distributed across multiple computer servers worldwide, rather than in a centralized server such as GenBank.

A joint venture between the Sanger Centre and the European Bioinformatics Institute, both at Hinxton near Cambridge, Ensembl aims to provide a single reference map of the human genome on to which participating scientists can anchor 'annotations' describing the predicted function and structure of gene sequences.

This Distributed Sequence Annotation System (DAS), which is being developed by
Lincoln Stein, a bioinformatician at Cold Spring Harbor Laboratory in New York, will be rolled out next month at the International Conference on Intelligent Systems for Molecular Biology in La Jolla, California.

A software 'plug-in' will then be made available to allow users to zoom in on any part of the genome. As well as accessing details on the DNA sequence, together with author information, they will be able to compare apparent contradictions between different third-party annotations. The results will be returned in standard formats from all participating DAS servers, so that the graphics and displays look the same.

The first two DAS servers to join the scheme will be at Ensembl and the Oak Ridge National Laboratory in Tennessee. http://www.ensembl.org/

| http://stein.cshl.org/das/ 


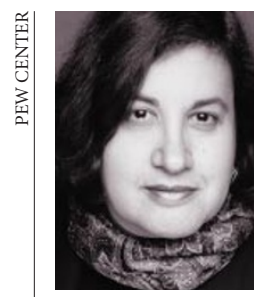

to cut carbon emissions "We're making a lot of progress here," says Dan Lashof, head of the climate-change programme at the Natural Resources Defense Council, pointing to Claussen: targets recent bipartisan calls in for emissions the Congress for reducmust be realistic. tions in power-plant emissions.

Jennifer Morgan, director of the World Wildlife Fund's climate-change campaign, also believes the Kyoto Protocol can work. "We should be focusing on a domestic plan to meet the targets, not on changing them," she says.

But the Global Climate Coalition, the industry group that has opposed binding action to cut carbon emissions, said that Claussen's statements bore out its early warnings about the Kyoto Protocol. "We agree with her that the targets are simply unrealistic," says Connie Holmes, chair of the coalition's board. "In the last three years, they have become more unrealistic - and not just for the United States.”

i http://www.pewclimate.org/media/

transcript_riia.html

\section{Proposal for US patent office could help cut waiting time}

Paul Smaglik, Washington

Anyone who has recently applied for a US patent - particularly in high-tech fields or biotechnology - will have waited a long time to learn of their request's fate. A congressman is now proposing to address this problem by allowing the United States Patent and Trademark Office (USPTO) to keep all the fees that it raises.

The move would help to increase the number of examiners - without this, warns the office, the backlog of applications is likely to grow even longer. Applications have increased by $12 \%$ in the past year alone, and the time for processing each one has grown from 18 months in 1995 to 26 months now.

Up to now, the patent office has always handed over a portion of its income to the government. But the precise percentage has varied, creating difficulties with long-term hiring commitments.

In the next financial year, which begins in October, the USPTO expects to take in about $\$ 1.2$ billion. But the House, Senate and President Bill Clinton's administration disagree over how much the agency should keep. The House is suggesting $\$ 905$ million, whereas the Senate last week voted to allow it to retain all but $\$ 33$ million; the president's budget calls for the USPTO to give up \$113 million.

Representative Howard Coble (Republican, North Carolina) has put forward a bill that would allow the USPTO to spend everything it earns. The administration has not commented on this proposal. But in a letter to Coble earlier this summer, USPTO commissioner Todd Dickinson warned of dire consequences if the House's budget were adopted, as the office would have to impose a hiring freeze and reduce overtime.

Demand for patents is especially heavy in genomics, where there is already a backlog of 20,000 applications for patents on genes, says Lila Feisee, a spokesperson for the Biotechnology Industry Organization.

Analysing these applications requires more people and better software, adds Feisee, a former USPTO examiner. "There's such an outcry over gene patents now that it's important to do it right," she says.

\section{Physicists celebrate detection of elusive 'final' particle}

\section{Colin Macilwain, Washington}

High-energy physicists are declaring 'full house' after detecting the last remaining basic building block of matter predicted by the Standard Model. A team at Fermilab outside Chicago has seen the elusive tau neutrino for the first time.

The DONUT (Direct Observation of the $\mathrm{Nu}$ Tau) team of 54 physicists from the United States, Japan, South Korea and Greece announced last week that they had found the kinked, millimetre-long decay tracks of four tau leptons - produced when an iron nucleus and a tau neutrino collide - after analysing millions of such possible events.

The Standard Model of fundamental particles and their interactions predicts the existence of 12 'fermions' - the basic building blocks of matter - and four 'vector bosons', which carry force. The tau neutrino, which belongs to a class of fermions called leptons, was the last to evade detection.

"Finding the tau neutrino is very important and exciting," says Martin Perl of Stanford University, California, who won the 1995 Nobel Prize in Physics for his discovery of the tau lepton. "DONUT was not an easy experiment, and now it opens a whole new world. We might have a chance of learning more about all other particles."

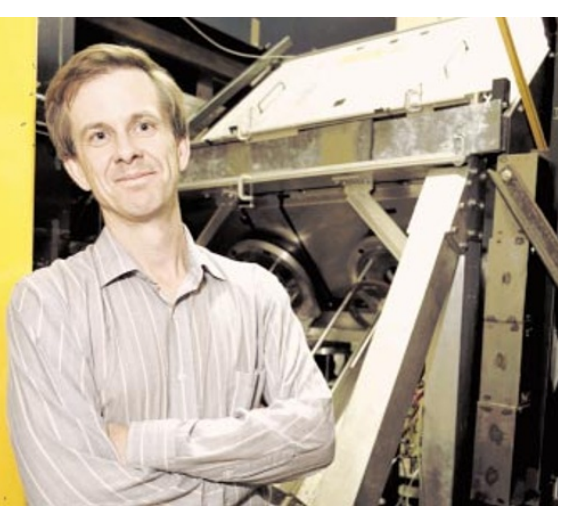

DONUT delight: spokesman Lundberg describes discovery as 'the proverbial needle in a haystack'.

In particular, the finding may assist the burgeoning field of neutrino physics. Early results from the SuperKamiokande experiment in Japan suggest that neutrinos may have mass (see Nature 391, 123; 1998). To test this, physicists in Japan, Europe and the United States are planning experiments to observe the oscillation of one type of neutrino to another.

The DONUT experiment began in 1997, by sending a high-energy proton beam from Fermilab's main particle accelerator, the Tevatron, into a block of tungsten.
Researchers filtered a beam of neutrinos out of the resulting mêlée, and this was passed through a target of iron sandwiched with layers of emulsion.

The DONUT team identified 1,000 events of interest and took the emulsion plates, which work like three-dimensional photographic film, to Nagoya University in Japan for analysis. "It was the proverbial needle in a haystack," says Fermilab's Byron Lundberg, spokesman for the experiment.

High-energy physicists are now switching their attention to the Higgs mechanism, an extension to the Standard Model, which explains how particles acquire mass. This involves exchanges of a particle called the Higgs boson, the search for which will resume at a revamped Tevatron next year. CERN, the European Laboratory for Particle Physics near Geneva, will join the hunt in 2005 with its Large Hadron Collider.

Meanwhile, some researchers are excited by 'supersymmetry', a theory outside the Standard Model. This predicts that every fermion has a supersymmetric boson counterpart, and vice versa. Experiments at CERN's Large Electron-Positron collider have hinted at a counterpart to the bottom quark - although previous hints have turned out to be statistical fluctuations. 